\title{
Digital and real-habitat modeling of Hipparchia statilinus based on hyper spectral remote sensing data
}

\author{
L. Luft ${ }^{1,3}$ - C. Neumann ${ }^{2}$ - S. Itzerott ${ }^{2}$ A. Lausch ${ }^{4}$ D. Doktor ${ }^{4}$. \\ M. Freude ${ }^{5}$ N. Blaum ${ }^{3} \cdot$ F. Jeltsch ${ }^{3}$
}

Received: 19 May 2014/Revised: 19 May 2015/Accepted: 7 July 2015/Published online: 21 August 2015

(C) Islamic Azad University (IAU) 2015

\begin{abstract}
The abandonment of military areas leads to succession processes affecting valuable open-land habitats and is considered to be a major threat for European butterflies. We assessed the ability of hyper spectral remote sensing data to spatially predict the occurrence of one of the most endangered butterfly species (Hipparchia statilinus) in Brandenburg (Germany) on the basis of habitat characteristics at a former military training area. Presenceabsence data were sampled on a total area of $36 \mathrm{~km}^{2}$, and $N=65$ adult individuals of Hipparchia statilinus could be detected. The floristic composition within the study area was modeled in a three-dimensional ordination space. Occurrence probabilities for the target species were predicted as niches between ordinated floristic gradients by using Regression Kriging of Indicators. Habitat variance could be explained by up to $81 \%$ with spectral variables at a spatial resolution of $2 \times 2 \mathrm{~m}$ by transferring PLSR models to imagery. Ordinated ecological niche of Hipparchia statilinus was tested against environmental
\end{abstract}

L. Luft

lluft@uni-potsdam.de

1 Sielmann's Naturlandschaft Döberitzer Heide gGmbH, Athener Straße 2, 14641 Wustermark, Germany

2 Helmholtz-Zentrum Potsdam-Deutsches GeoForschungsZentrum GFZ, Section 1.4, Telegrafenberg, 14473 Potsdam, Germany

3 Institute for Biochemistry and Biology, Department of Plant Ecology and Nature Conservation, University of Potsdam, Maulbeerallee 2, 14469 Potsdam, Germany

4 Helmholtz Centre for Environmental Research -UFZ, Permoserstrasse 15, 04318 Leipzig, Germany

5 Landesamt für Ländliche Entwicklung, Landwirtschaft und Flurerneuerung, Müllroser Chaussee 54, 15236 Frankfurt (Oder), Germany predictor variables. $N=6$ variables could be detected to be significantly correlated with habitat preferences of Hipparchia statilinus. They show that Hipparchia statilinus can serve as a valuable indicator for the evaluation of the conservation status of Natura 2000 habitat type 2330 (inland dunes with open Corynephorus and Agrostis grasslands) protected by the Habitat Directive (Council Directive 92/43/EEC). The authors of this approach, conducted in August 2013 at Döberitzer Heide Germany, aim to increase the value of remote sensing as an important tool for questions of biodiversity research and conservation.

Keywords Habitat gradients - Military areas · Natura $2000 \cdot$ hyper spectral $\cdot$ Vegetation continuum $\cdot$ Kriging

\section{Introduction}

Military conversion areas represent valuable natural and seminatural habitats including large and unfragmented biotopes (European Commission 2005a, b; Warren et al. 2007; Havlick 2011). Several former military areas are today preserved as nature conservation areas and under the protection of the Natura 2000 network which is legally based on the Council Directive 92/43/EEC on the Conservation of Natural Habitats and of Wild Fauna and Flora (the Habitats Directive, European Commission 2005a) and the Council Directive 79/409/EEC on the Conservation of Wild Birds (the Birds Directive, European Commission 2009). Disturbance regimes of military land use as mechanical disturbances by heavy vehicles, fire caused by exploding munitions and military exercises caused the development of ecosystems as heathlands and areas of bare sand, representing characteristic open-land habitats for rare and threatened plant and animal species (Walker and 
Pywell 2000; Carvell 2002; Warren et al. 2007). However, especially after the end of the cold war, the abandonment of military areas resulted in succession processes considerably affecting a wide range of species (Tucker and Heath 1994; Poole et al. 1998; LUGV 2011).

Especially, butterflies are affected by increasing succession. They are adapted to specific food and habitat requirements at different stages of their life cycle (Van Swaay et al. 2010). Van Swaay et al. (2010) especially point out the invasion of shrubs and trees as to be the main long-term threat to butterflies. Therefore, our target species Hipparchia statilinus HUFNAGEL (Lep., Satyridae) serves as an indicator for habitat qualities of open landscapes. Hipparchia statilinus is adapted to xerothermic places consisting of patchy vegetation of Corynephorus canescens with dried moss or pure sand, which makes it a characteristic indicator for the evaluation of the conservation status of habitat type 2330 (European Habitat Directive: inland dunes with open Corynephorus and Agrostis grasslands).

Bellis et al. (2008) stated that nature conservation and management can be the most effective, when efforts are focused on the most suitable habitats for the species of concern. However, the limited accessibility at military areas due to exploding munition remaining in the ground makes it difficult to evaluate habitat qualities for our target species and hence to derive suitable management activities.

Thus, we focus on remote sensing data. Wang et al. (2013) show that habitat modeling based on remote sensing data has already proven to be a valuable instrument for environmental modeling and monitoring. There is an increasing use of remote sensing in ecological research at species level worldwide (Wang 2012; Mücher et al. 2013). Especially in North America, there are several promising monitoring approaches as, e.g., the "NPScape" project by the US National Park Service and NASA as well as adjacent projects in Canada (by Parks Canada Agency and the Canadian Space Agency) aiming to enhance the use of remote sensing data for facilitating monitoring at National Parks (see Gross et al. 2012). Habitat suitabilities were evaluated for, e.g., mammals as gray wolf (Mladenoff et al. 1995) or brown bear (Posillico et al. 2004) and birds as great bustard (Osborne et al. 2001) or eagles (Balbontin 2005).

Unfortunately, there is a lack of studies evaluating habitat suitability at smaller scales as for insect species with smaller habitat sizes and ranges. One example was presented in Luoto et al. (2002), who tested the ability of multispectral Landsat data and geographical information system (GIS) techniques to explain butterfly distributions and predict the occurrence of the butterfly species Parnassius mnemosyne in independent test areas. Spectral coherence analyses provide strong evidence that spectral information can be used for an area-wide mapping of plant species diversity from field to landscape scale (Lausch et al. 2013; Rocchini et al. 2010). From this, it can be concluded that a detailed habitat characterization on the basis of hyper spectral signatures offers a great potential. However, most of the existing studies use habitat classification based on binary land cover classification, where suitable classes are used as indicators for habitat establishment (Kerr and Ostrovsky 2003; Gottschalk et al. 2005). The underlying hypothesis is that land cover classes have ecological relevance to the occurrence of target species. Ecological categories can then be used to map habitat pattern, its temporal variability as well as habitat status parameter (Weiers et al. 2004). Furthermore, remote sensing techniques are suitable for empirical coherence analysis with presence/absence data on quantitative metrics such as Normalized Differenced Vegetation Index (NDVI) (e.g., Cumming 2000; Sardà-Palomera et al. 2012). Nevertheless, by now, there is no quantitative measure of plant species cover realized as habitat factor due to limiting spatial and spectral resolutions of commonly used remote sensing data. Complex habitat conditions are often described by only a few environmental parameter categories or classifications. They do not satisfy the precise habitat demands at species level (see Bellis et al. 2008). Classification always means that different habitats (characterized by, e.g., different stages of succession) are assigned to the same vegetation class and differentiations at small scales, as they are necessary for evaluating habitat qualities for small species as butterflies, are not possible. First quantitative measures such as remote sensing-based vegetation indices are difficult to interpret because of their multidimensional correlation structures (one index represents canopy characteristics that can be related to different environmental factors, e.g., plant stress, biomass, fractional cover, nutrition gradient). Using a priori assumption of ecological relevancy to overcome lacks of understanding may mislead in identifying significant habitat parameter in complex ecosystem dynamics. In contrast, hyper spectral sensors offer finer spectral measurements in hundreds of spectral bands that allow for a detailed representation of habitat characteristics (Mücher et al. 2013).

Another problem which hinders effective management resulting from remote sensing analysis is the existing lack of cooperations between remote sensing specialists and ecologists to define specific habitat demands of a species and potential sources of error (Vanden Borre et al. 2011). Bellis et al. (2008) agree that remote sensing projects are not yet able to satisfy the real needs of ecologist. The potential contribution to habitat modeling have by far not been exploited yet (Hepinstall and Sander 1997; Luoto et al. 2004). 
We summarize that remote sensing techniques used in the concern of nature conservation issues neither meet the demands of high spatial and spectral resolution to be able to evaluate habitat qualities at small scales nor the demands of ecologist on the real-habitat requirements of species as Hipparchia statilinus.

Therefore, the aim of this approach is to combine terrestrial mappings with hyper spectral remote sensing data to spatially predict the occurrence of our target species Hipparchia statilinus on the basis of habitat characteristics. To demonstrate the potential of increased information content in hyper spectral signatures, a modeling of floristic gradients in a vegetation continuum shall be performed. For the first time, we want to show how habitat preferences can be quantified in an ordination space that holds the generalized composition of plant species for the vegetation continuum. For an a posteriori identification of environmental parameter that influences habitat preferences, we superimpose ordinated gradient structure with known habitat characteristics. We use terrestrial mappings to generate presence/absence data of our target species. These distribution data and habitat qualities from the view of a target species shall be evaluated. Thus, habitat models including the real-habitat requirements are generated, and the probability of occurrence of the target species can be estimated (Morrison et al. 1998; Schröder 2000; Schröder and Reineking 2004). Building predictive models of habitat qualities will contribute to the preservation of Hipparchia statilinus especially on military areas.

\section{Materials and methods}

\section{Study area}

The nature conservation area "Döberitzer Heide" covers about 3600 ha and is directly neighboring the western border of Berlin, Germany (Fig. 1). It was used for military activities for more than 300 years. Intensive disturbance regimes of military land use generated heathlands and sandy areas on one hand and absence of infrastructure or agriculture on the other hand. The resulting landscape is nutrient-poor and unfragmented, and the impressive structure diversity serves as habitat for more than 5000 floristic and faunistic species (LUGV 2011). Due to explosive contaminants remaining on the area, any human access is forbidden. Since 2004, a "New Wilderness" is created by Heinz Sielmann Foundation (Simmat 2011) where the megaherbivore species European bison (Bison bonasus), przewalski horse (Equus ferus przewalskii) and red deer (Cervus elaphus) were reintroduced in order to affect the landscape structure by counteracting natural succession processes. It aims to preserve a good ecological status of present Natura 2000 habitats.

\section{Target species Hipparchia statilinus}

Hipparchia statilinus HUFNAGEL (Lep., Satyridae) is a characteristic species of large-scale and sandy places as they are typical for military areas (Steiner and Trusch 2000; Gelbrecht et al. 2001a, b). Records of this species are known from all European countries besides Scandinavia, Denmark, Estonia, Latvia, Great Britain and Luxembourg (Steiner and Trusch 2000). Hipparchia statilinus is a stenoecious species and adapted to large, dry and warm habitats as, e.g., pioneer stages of Koelerio-Corynephoretea (Schubert et al. 1995). Main habitats for the larvae of Hipparchia statilinus are inland dunes and early succession stages of end- and ground moraines and secondary habitats at military training areas, clearings at minings or sandy and gravel pits (Kühne and Gelbrecht 1997). Grass species as Corynephorus canescens or Calamagrostis epigejos are used as food plants for the caterpillars (Kühne and Gelbrecht 1997). The adult butterflies use open, sandy areas, sites burned in former times (warming quite fast in the sun) or sandy paths as well as edges of pine forests (Kühne and Gelbrecht 1997).

Hipparchia statilinus is one of 44 "near threatened" species in Europe (van Swaay et al. 2010) and listed as "threatened by extinction" by the Red List of Germany and Brandenburg (Gelbrecht et al. 2001b; Binot-Hafke et al. 2011). Kühne and Gelbrecht (1997) identify a loss of $45 \%$ of the occurrences in Mark Brandenburg since 1980 and therefore point out the urgent need for concrete measures for habitat protection. At Döberitzer Heide, $N=6$ individuals were mapped from 1995 to 2010.

\section{Database: spectral data}

The flight campaign for hyper spectral imageries occurred on June 4, 2011, between 10:00 and 12:30 p.m. Universal Time. The imaging spectrometer was an AISA DUAL (UFZ Leipzig) sensor ranging from visible $(400 \mathrm{~nm})$ to short-wave infrared $(2500 \mathrm{~nm})$ in 367 spectral bands. Mean flight altitude was $1500 \mathrm{~m}$ above sea level. The final product size was resampled to $2 \times 2 \mathrm{~m}$ after geocoding and mosaicking of single flight stripes. At sensor radiance from internal calibration was translated to top of the canopy reflectance applying radiative transfer modeling (ATCOR4), followed by a nonlinear approximation to reference spectra that were collected during overflight. Reflectance signatures were finally extracted for every field plot, and additional spectral variables were calculated using continuum removal (Clark et al. 1987) and first Savitzky-Golay derivation (Savitzky and Golay 1964). After masking 


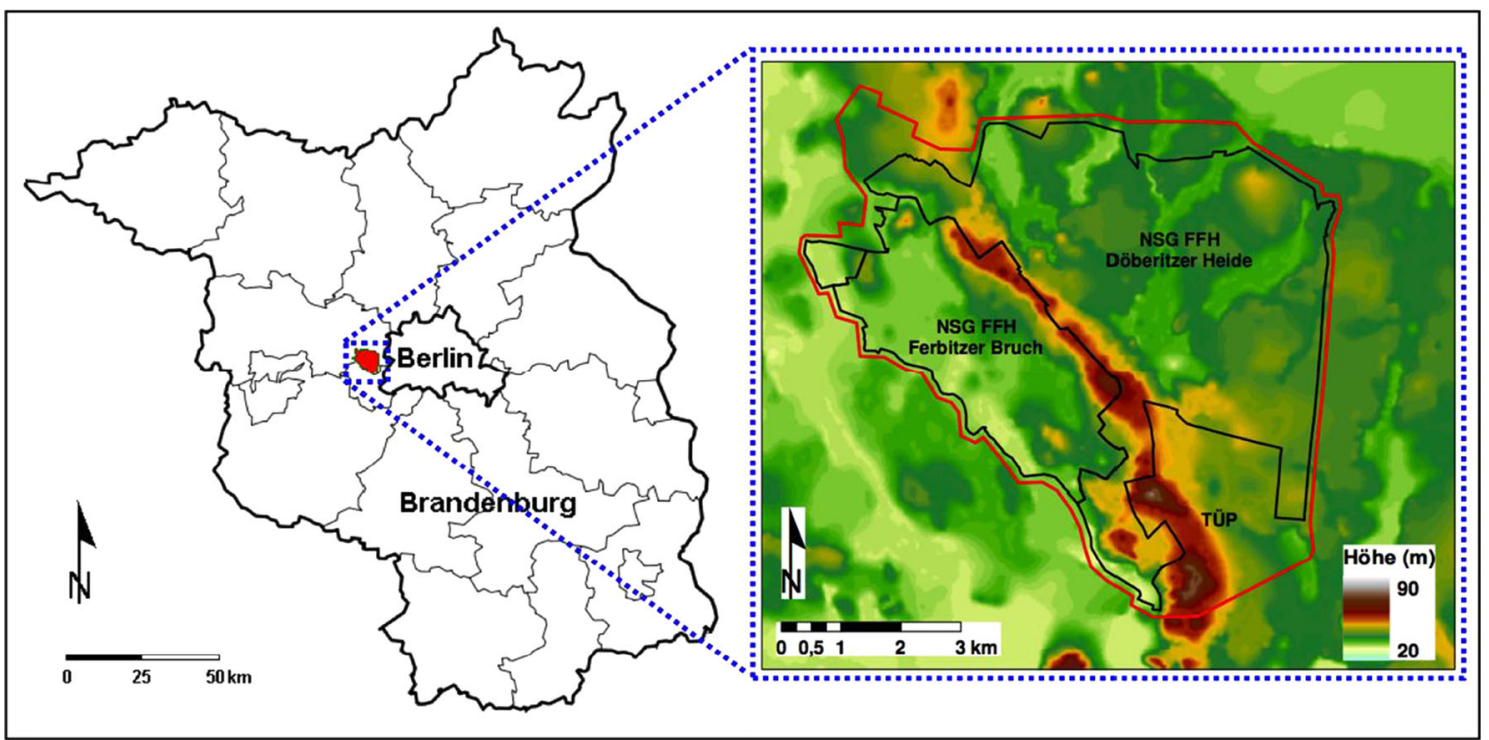

Fig. 1 Study area Döberitzer Heide in Brandenburg (Statistisches Bundesamt), black line border of the nature reserves and FFH areas, red line former military training area (Landesvermessungsamt Brandenburg) (Neumann 2010)

atmospheric water bands $(1.34-1.45 / 1.75-2.00 />2.4 \mu \mathrm{m})$, a total number of 576 spectral predictor variables were used to model ecological responses.

\section{Database: Hipparchia statilinus distribution data samplings}

We conducted a prestudy in August 2011 to receive first information on the habitat preferences and number of individuals of Hipparchia statilinus in our study area. We used multispectral classification data derived by Quickbird satellite in 2010. The classes "bare sand," "dry grassland rich on cryptogams" and "dry grassland poor on cryptogams" (Frick et al. 2005; Frick 2007) were summarized as "potential habitats of Hipparchia statilinus." Subsequently, we evaluated the percentage coverage of the "potential habitat" class per $100 \mathrm{~m} \times 100 \mathrm{~m}$ grid squares. Assuming that the higher the coverage of suitable habitats per raster, the higher the probability of occurrence of Hipparchia statilinus in this raster unit, we transmitted the coverage into four categories of probabilities of occurence: (1) 0-15\%: none; (2) 15-30\%: few; (3) 30-50\%; medium; and (4) $>50 \%$ : high. For each class, we randomly selected four raster units. In total, we surveyed $N=16$ areas of four different probability classes in August 2011. This information was used to clarify the habitat demands of Hipparchia statilinus in the following studies.

In 2012, we intended to quantitatively prove the supposed linear relation of habitat preference and probability of occurrence. To face the challenge of monitoring a huge area in a short time (limited flight time of Hipparchia statilinus: about 4 weeks), we hold the "1st Döberitzer
Heide Butterfly-Days" from August 10-12, 2012. During these days, experts and interested people throughout Germany were invited to participate in mapping Hipparchia statilinus at all habitats up to $15 \%$ probability (probability classes 2-4 from the prestudy 2011). Supported by experts for explosive munition and the federal armed forces, we were able to enter the core zone as well as the still used part of the military training area. For this purpose, the area was subdivided into 13 units $(\mathrm{A}-\mathrm{N})$ to coordinate the terrestrial sampling teams (see Fig. 2). The samplings were located by Global Positioning System (GPS), and at each location, four pictures of the surroundings were taken. In addition to the sampled presence data, we received absence data per random generator for not inhabited raster units.

\section{Habitat modeling}

\section{Step 1: determining vegetation continuum}

For this study, a comprehensive database including spectral information on the vegetation of the Döberitzer Heide was used which was established between 2007 and 2011 (Neumann et al. 2013). Vegetation data were sampled on 125 reference plots comprising moist and dry habitats of open-land communities. In total, the cover of 226 different species was estimated for $1 \mathrm{~m}^{2}$ sample areas. To ensure the recognition of characteristic floristic composition by hyper spectral airborne imagery (typically $2-4 \mathrm{~m}$ spatial resolution) on plot scale, a homogenous surrounding of each plot in a $5-\mathrm{m}^{2}$ area concerning plant composition, bare soil and litter cover was realized. Subsequently, we applied nonmetric multidimensional scaling (NMDS) to project plot by 


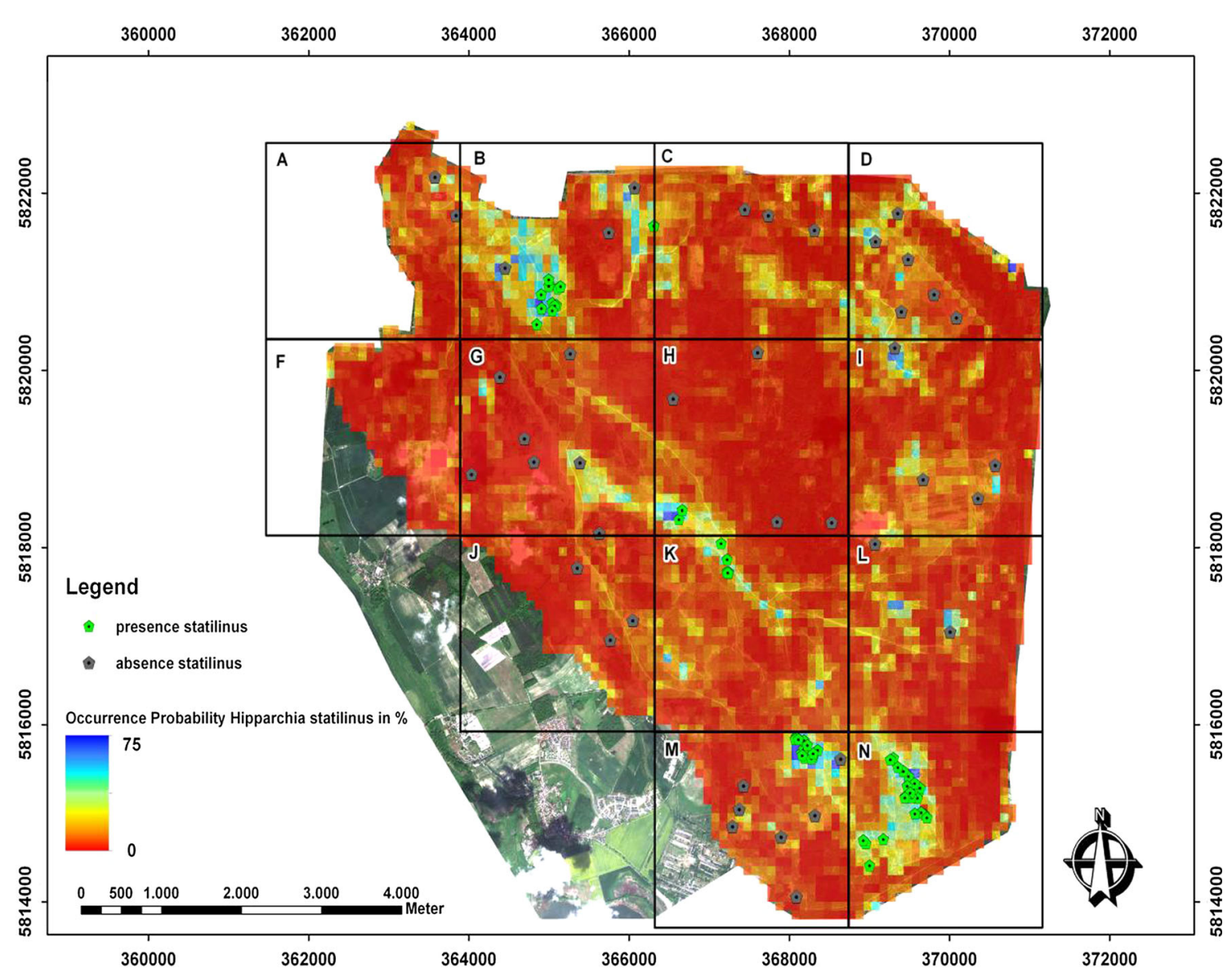

Fig. 2 Results of the terrestrial samplings of $N=65$ individuals of Hipparchia statilinus in 2012 (green), added by $N=41$ randomly selected absence data (gray), uniformly distributed over all occurring vegetation classes. Database is a Quickbird satellite image (2010)

species matrix into a three-dimensional ordination space. Therein species similarities were rank-ordered using BrayCurtis distance metric. Final ordination topology was calculated after 1000 random start configurations by minimizing residuals to original rank order (Kruskal 1964).

\section{Step 2: spectral prediction of vegetation continuum}

Ordinated score axes were modeled by means of Partial Least Squares Regression (PLSR) (Wold 1966) using derived spectral predictor variables. Three individual PLSR models were calibrated regressing axis scores against spectral predictors. In order to increase model stability with regard to predictive ability a variable selection was iteratively performed maximizing $R^{2}$ of final model in an internal Leave-one-Out (LOO) cross-validation (Schmidtlein et al. 2012) (see Luft et al. (2014) for a detailed description of applied spectral predictor derivation). Final models were then transferred to image spectra to spatially predict ordination scores for presence/absence locations. combined with a map of categorized occurrence probabilities of Hipparchia statilinus: (1) 0-15\%: none; (2) 15-30\%: few; (3) $30-50 \%$; medium; (4) $>50 \%$ : high and subdivided into units $A-N$ to coordinate field sampling teams

\section{Step 3: determining habitat occurrence}

We assume that Hipparchia statilinus occupies distinct regions of ordinated floristic arrangement as a consequence of habitat establishment. Hence, the geographic plot locations for presence/absence data were projected to ordination space dimensions using spectral predictions on image spectra. Presence/absence locations could be modeled with distinct coordinates in a three-dimensional NMDS ordination space. We further assume that data locations can be understood as a spatial random variable (Matheron 1971) with binary information content that is realized on modeled score coordinates. As a consequence, we could describe spatial variance structure of occurrence pattern by spatial correlation functions. Due to spatial nonstationarity in score gradients, we first modeled spatial trend using a trend surface model on the score axes. Subsequently, we applied three-dimensional variography on the model residuals for the determination of an appropriate variogrammodel that can be used to model the occurrence distribution in 
geostatistical Kriging (Matheron 1963). The binary response was modeled for every 0.01 score voxel using Regression Kriging of Indicators (Hengl et al. 2007). Thereby, the variogrammodel of residuals was used to prove a significant spatial correlation of habitat preferences in ordinated floristic continuum in addition to a logistic trend surface model. Kriging weights were calculated for all Hipparchia statilinus samples on logit-transformed membership values. The resulting weighted average was finally back-transformed to occurrence probabilities ranging from 0 to 1 .

\section{Predictor variables}

We now defined $N=12$ predictor variables known or expected (conforming to expert literature and knowledge) to influence Hipparchia statilinus habitat suitability, especially focusing foraging and behavior in larval and adult butterflies habitats. The variables were subclassified into (1) vegetation metrics and structure, (2) topographic parameters and (3) distance metrics:

\section{Vegetation metrics and structure,}

Conforming to Kühne and Gelbrecht (1997), Hipparchia statilinus is adapted to xerothermic places for foraging and nesting. Further, egg deposition behavior is dependent on sandy areas covered by moss to a certain degree (Steiner and Trusch 2000). Hence, we identified the variables "moss," (Polytrichum piliferum) "lichen" (Cladonia spp.), "pioneer stages" (represented by Corynephorus canescens) and "bare soil" as to probably influence the habitat quality for the target species. Steiner and Trusch (2000) named Polytrichum piliferum, Cladonia ssp. as well as Corynephorus canescens as to be preferred species for egglaying.

\section{Topographic metrics}

The topographic metrics serve as additional parameters to evaluate relevance of wind and solar radiation. Six variables namely "elevation," "slope," "northness," "wetness," "plan curvature" and "profile curvature" derived from a digital elevation model DGM based on a topographic map (1:10.000) were identified.

\section{Distance metrics}

Calluna vulgaris is one of the food plants of Hipparchia statilinus, and habitats are known to be socialized with Calluna appearances (Kühne and Gelbrecht 1997). Therefore, the "distance to heathlands" seems to be relevant for the habitat quality of our target species. The variable "distance to forests" is an important parameter because Hipparchia statilinus is known to inhabit biotope complexes (Weidemann 1995) and can also be found sitting at the stem of pines or on poplars (Kühne and Gelbrecht 1997). On the other hand, forests can influence habitat suitability in a negative way since it interrupts migration between habitats through dense forest areas.

Subsequently, we tested the predictor variables within the ordinated floristic continuum to derive correlation structures to habitat occurrence probability. For this purpose, predictor variables are projected to ordinated plot locations and related to probability values. The Pearson product moment correlation and $p$ value were calculated to assess predictive power and significance of single predictor variables. Highly diagnostic habitat parameters were identified for the establishment of an appropriate Hipparchia statilinus habitat.

\section{Results and discussion}

\section{Distribution data}

Our approach showed that we were able to detect $N=65$ records of Hipparchia statilinus in our study area. Figure 2 confronts them to $N=41$ randomly sampled absence data which are uniformly distributed over all occurring vegetation classes.

\section{Habitat modeling step 1: determining vegetation continuum}

The floristic pattern of the study area is represented in a three-dimensional ordination space. Score values were standardized between 0 and 1 in order to represent grayscale values for a RGB color composite in ordination dimensions. Ordinated plot arrangement occurs in distinct pattern that can be allocated to color clusters with transition to adjacent communities (Fig. 3).

Selected plant species are visualized according to their cover values to show floristic habitat separation ability of ordinated plot locations. The bigger the plot size, the higher the species cover of visualized plots. It can be shown that occurrence clusters are characterized by unique color values that continuously transit to competing plant species. We conclude that habitat establishment can be determined in ordinated structures. As we do not introduce an ad hoc hypothesis about Hipparchia statilinus habitat preferences, we subsequently model ordination axes via spectral signatures that are allocated to individual plots (Fig. 4). Score variance on the first axis can be explained to $81 \%$ in LOO cross-validation using four latent components. The rootmean-square error of prediction (RMSEP) in LOO crossvalidation amounts to 0.46 . The predictive power of spectral variables is less in NMDS axis $2\left(R^{2}=0.44\right)$ and axis $3\left(R^{2}=0.39\right)$. For the second axis, six latent 


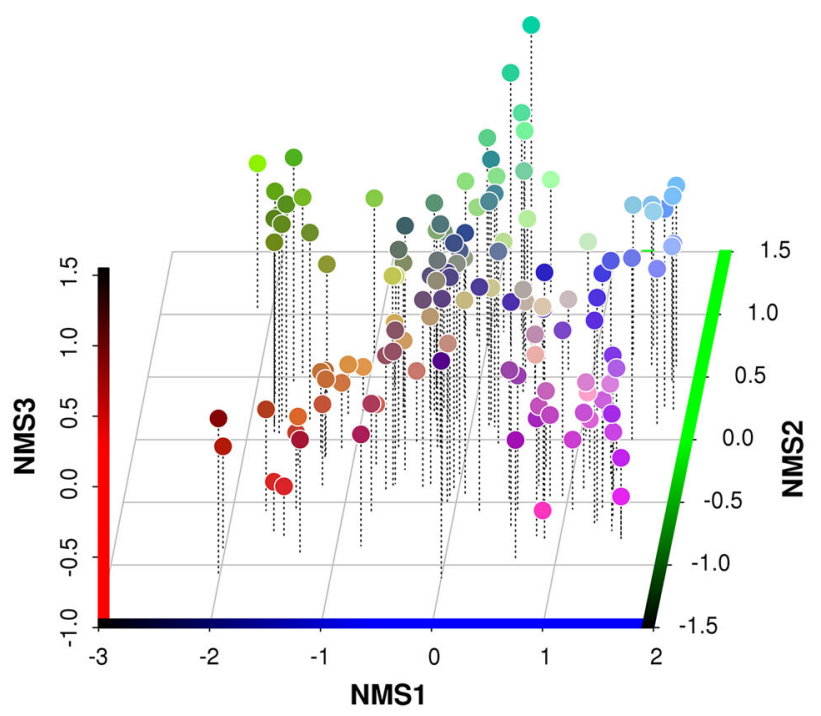

\section{Corynephorus canescens}

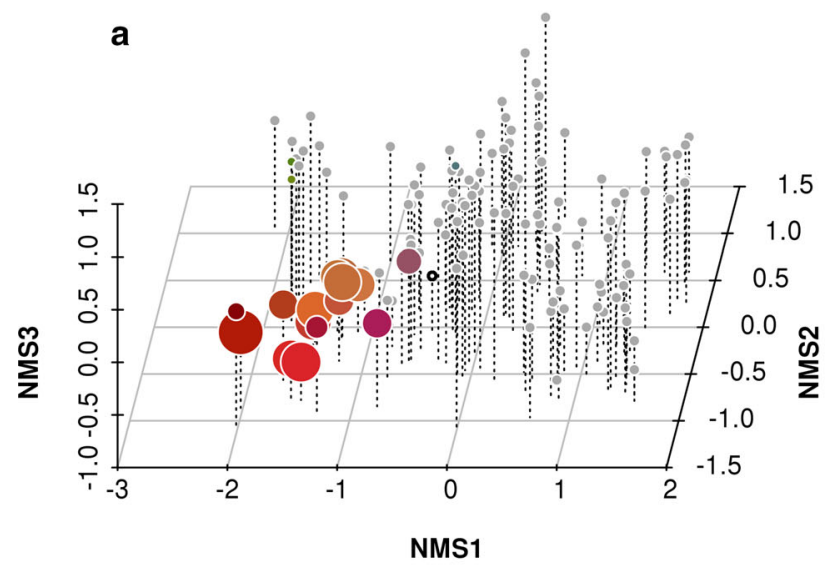

Calluna vulgaris

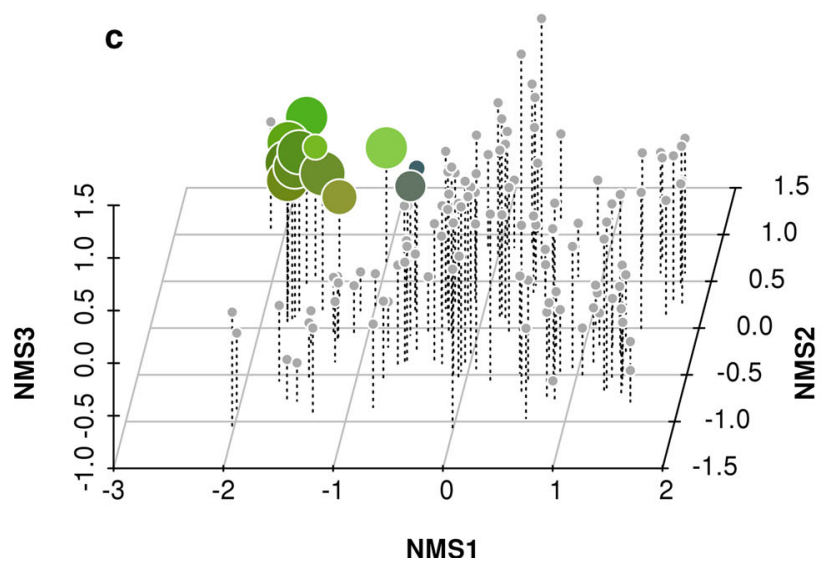

Fig. 3 Three-dimensional NMDS ordination in RGB space, color composite for 125 sites $\times 226$ species matrix along score axes; distribution of diagnostic plant species within ordination space.

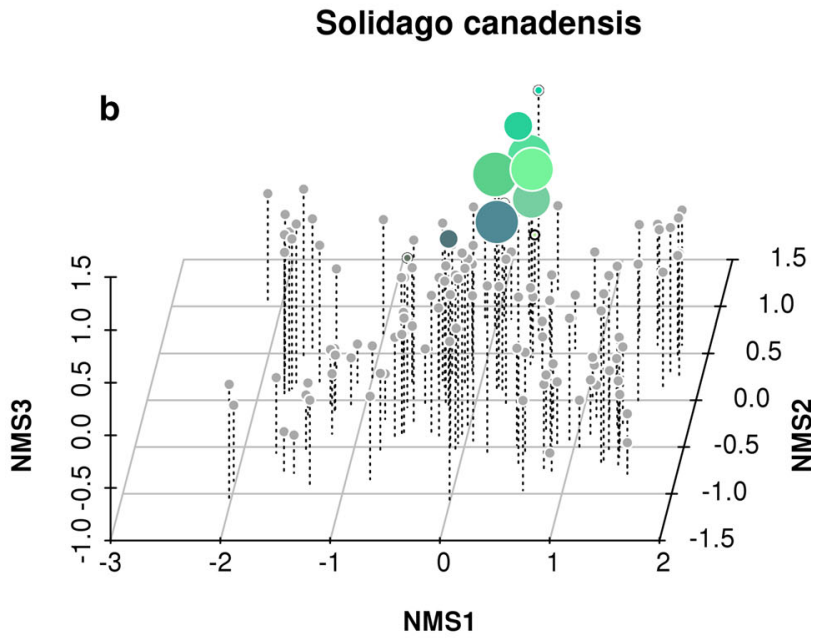

Carex agg.

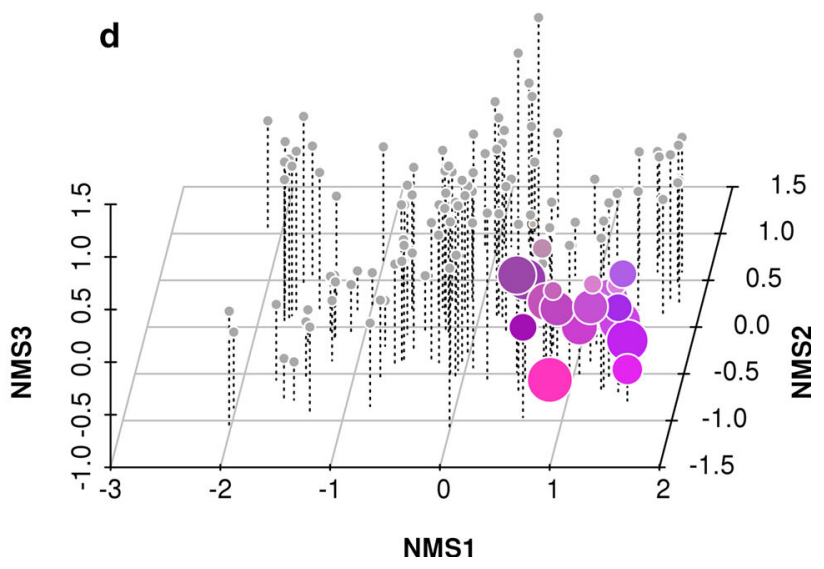

a Corynephorus canescens, b Solidago canadensis, c Calluna vulgaris, d Carex species; point size is positively correlated with fractional cover values 

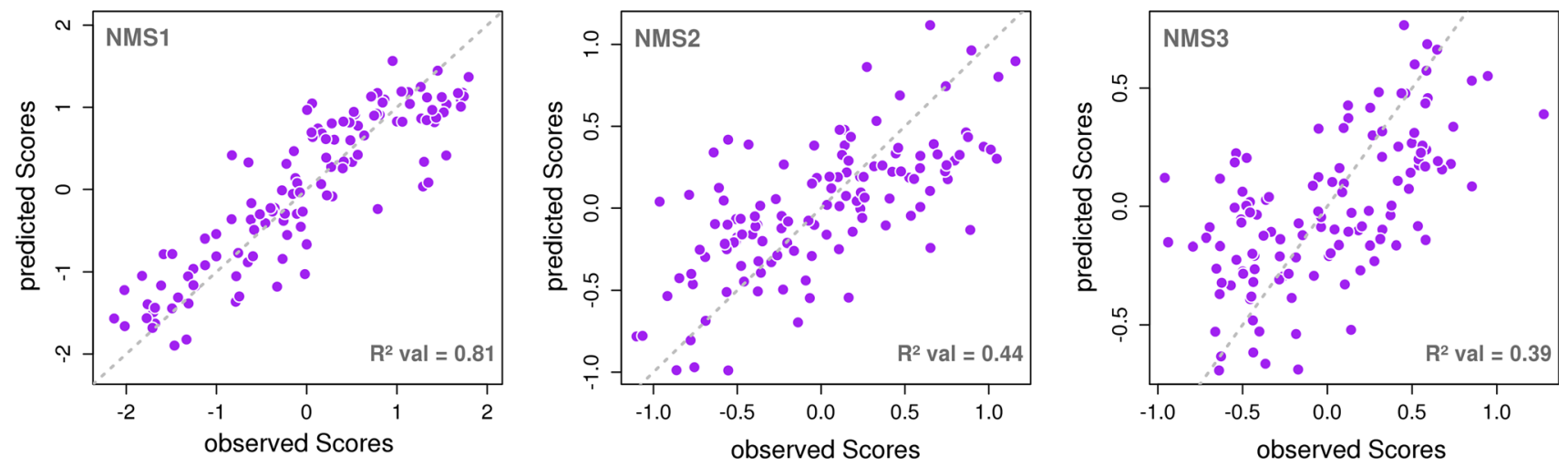

Fig. 4 Internal LOO cross-validation results for selected NMDS axes (1-3) predicted with PLS regression

components are selected as best solution resulting in a RMSEP of 0.41 . The number of latent components slightly decreases to 5 in the three-axis model $($ RMSEP $=0.37$ ). Selected models were subsequently applied to spectral variables derived from image spectra.

\section{Habitat modeling step 2: spectral prediction of vegetation continuum}

In Fig. 5, the floristic continuum of ordinated plot assemblages is transferred to the study area. Trees, water as well as shadow areas are masked in order to force spatial predictions within the boundary conditions of model calibration. The suggested RGB color space from Fig. 4 is completely projected by transforming single-axis model score predictions to composed RGB grayscale values.

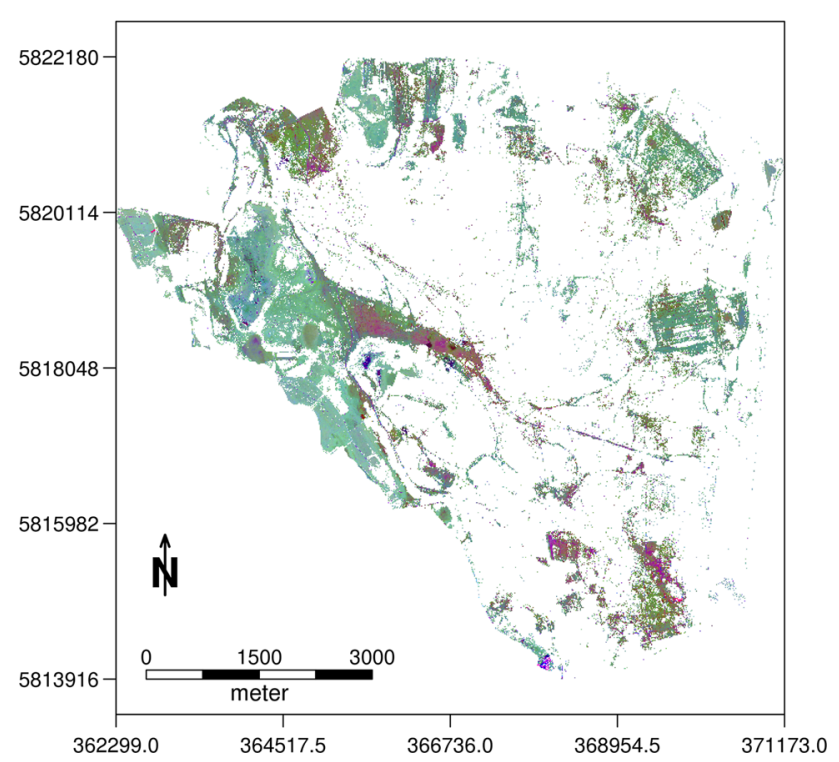

Fig. 5 Spatially explicit predicted floristic continuum (NMDS ordination) for open-land areas in the "Döberitzer Heide" on the basis of PLSR axis models transferred to $2 \mathrm{~m}$ AISA DUAL spectral imagery
Color values that are not occurring within ordination space visualization, especially light purple tones on bare ground areas, do not have adequate field plot representation because of only rare species cover. Nevertheless, they are placed in plausible areas of ordinated community arrangement.

\section{Habitat modeling step 3: determining habitat occurrence}

We subsequently extracted ordination space score coordinates for presence/absence data. On the basis of coordinate triples, Hipparchia statilinus habitat preferences were then projected into ordinated floristic continuum. The superposition of spatial Kriging interpolations for binary occurrence data and presence data points (arrows) can be seen in

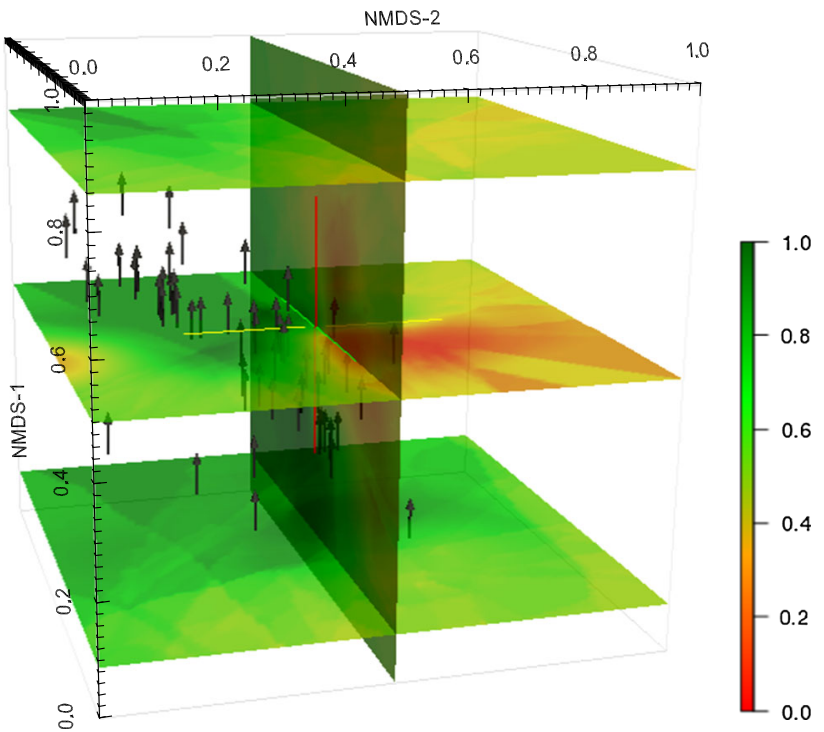

Fig. 6 Results of Regression Kriging of Indicators for 0.01 voxels, visualized in four ordination space slides displaying occurrence probability $(0,1)$; Hipparchia statilinus presence data (top of arrows) are overlayed to mark field survey positions 
Fig. 6 in four ordination space slices. Therein, presence locations are grouped to green tones, indicating a high probability of habitat suitability. A trend surface model was used as a first approximation on continuous voxel representation. All three score axes were significant with $p$ values $<0.05$. The final logistic coordinate model can explain Hipparchia occurrence variability to $78 \%$ using Nagelkerke $R^{2}$ (Nagelkerke 1991). The residuals to calibrated trend surface models were subsequently used to combine results with Krige interpolations. The underlying three-dimensional sample variogram was created with $n=15$ distance classes. A spherical variogram model was fitted against distance classes with 0.01 nugget variance and a range of 0.281 . Nugget variance only accounts to $5.5 \%$ to mean semivariance level (sill $=0.18)$. On that account, residual variance structure was used to additionally estimate ordination space probability, combining Indicator Kriging approach with logistic Trend Surface model.

In Fig. 7, different probability thresholds for presence (green) and for absence (red) occurrences within floristic ordination space are visualized. According to predicted voxel representation, habitat preferences can be determined in three-dimensional clouds of probability classes. Clear separations between preferred habitats and unqualified regions are detectable. When decreasing probability thresholds, transition within intermediate preferences occurs due to underlaying floristic gradients. In consequence, separation strength is positively correlated with extreme values in occurrence probability range. Finally, we transferred ordination space related probability values for Hipparchia statilinus to image pixels that are determined by predicted three-dimensional score axes (Fig. 8). Usually, expert knowledge is required to interpret spatial distribution pattern with regard to valuable plant communities and additional environmental parameter. In the present study, we demonstrate the a posteriori superimposition of habitat parameter (predictor variables) with the occurrence probability in the NMDS ordination space. In Fig. 9, the ordination space distribution of normalized gradient vectors for predictor variables is visualized on field plots. In general, plant species and bare ground cover gradients are clustered to down left parts of ordination space. They clearly reproduce floristic composition of pioneer stages with transition to heathland areas. Furthermore, they are limited to field plots where specific plant communities have established.

In our next step, we use ordination space topology to test predicted probabilities to its relation on forcing habitat factors. Each environmental predictor variable is projected to ordination space according $\mathrm{min} / \mathrm{max}$ normalized gradients in predictor specific ranges. This enables evidence estimation concerning the influence of several environmental parameters affecting occurrence probabilities of
Hipparchia statilinus. As result, univariate linear regression identifies 5 of 12 chosen habitat parameter to be significantly correlated $(p<0.05)$ with occurrence probability of Hipparchia statilinus (Fig. 10, purple color).

\section{Predictor variables: vegetation metrics and structure}

As considered before, the absolute Pearson product moment correlation is highest for bare ground and pioneer stages indicating most specific habitat characteristics (Fig. 10). This accords to (Kühne and Gelbrecht 1997) who showed that the egg deposition behavior of Hipparchia statilinus is depending on the amounts of pioneer vegetation. Adult butterflies also prefer large, open and dry habitats, and Corynephorus canescens is named the most important food and nesting plant species (Steiner and Trusch 2000). In contrast, we were surprised to find that moss and lichen cover cannot be efficiently used to describe suitable habitats although Kühne and Gelbrecht (1997) assumed the fast warming capacity of dry moss and bare sand to be an important parameter for habitat preferences of Hipparchia statilinus. Expert literature frequently points out the importance of moss, especially Politrichum piliferum. Conforming to them, the sites of egg findings were either without any vegetation or covered by moss and lichen to a high degree (Steiner and Trusch 2000). However, the coverage of moss as a single parameter is not significant. Rather, a complex patchy vegetation structure consisting of bare sand, moss and pioneer species as $\mathrm{Co}$ rynephorus canescens seems to be necessary to assure high habitat qualities.

\section{Predictor variables: topographic metrics}

Studies analyzing wind effects on butterflies are mostly restricted to migrating butterflies as Vanessa cardui or Vanessa atalanta (Williams 1961; Eitschberger et al. 1991) and do not mention the effect of wind exposition at small scales. Nevertheless, we supposed topographic parameter influencing the microclimate to be positively correlated with Hipparchia occurrences and assumed wind breaking as to be an important factor affecting Hipparchiás butterfly's behavior and habitat suitability. We find the three topographic indices "slope," "northness" and "elevation" to be able to describe Hipparchia habitat preferences at our study area. A uniform distribution of the parameter elevation and northness can be observed (Fig. 9). Northness is the circular decomposition of aspect values that allocates north aspects to 1 , east/west to 0 and south aspects to -1 on a linear scale. However, a slight gradient of elevation in NMDS 1 direction decreasing from left to right occurs. This conforms to Steiner and Trusch (2000) who found the 

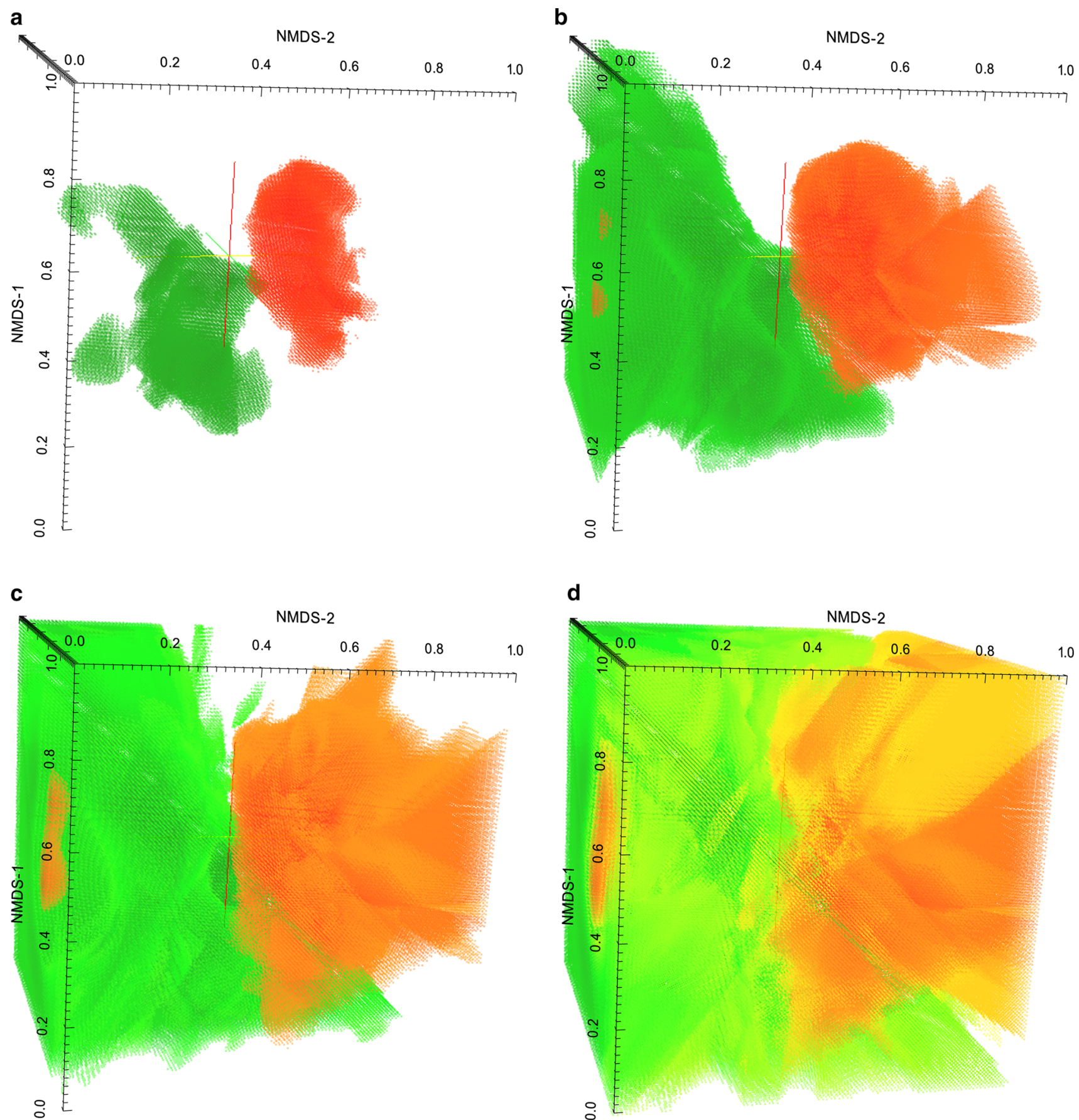

Fig. 7 Habitat preference clouds for predicted presence (green) and absence (red) probabilities of Hipparchia statilinus on the basis of Kriging probabilities; a $0<0.1 \& 0.9<1$, b $0<0.2 \& 0.75<1$, c $0<0.35 \& 0.6<1$, d $0<0.45 \& 0.55<1$

egg deposits mostly at plane or marginal southwestern exposed sites in Brandenburg. Higher variations in index ranges are represented in slope and curvature parameters. Thereby, slope maxima are allocated mostly to open pioneer stages, whereas convex curvatures (1) are located in the middle dominated by surrounding flat $(0.5)$ or concave (0) morphology. Since relatively high and sun-exposed southern sites enable fast warming, they seem to be preferred habitats for our target species.

\section{Predictor variables: distance metrics}

Distance parameter behavior varies in dependency on chosen distance class (see Fig. 9). Whereas the distance to 


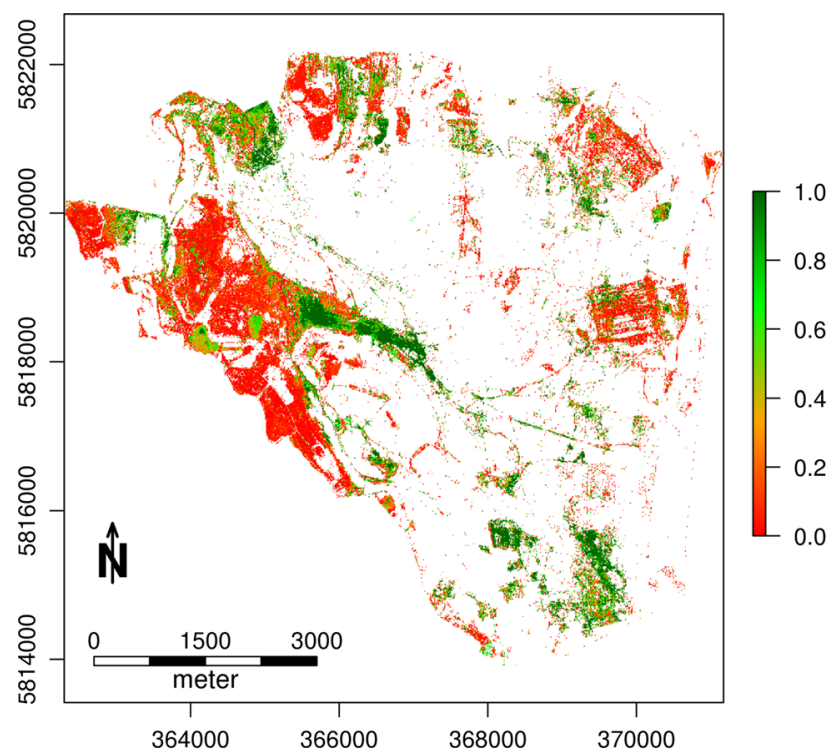

Fig. 8 Occurrence probability of Hipparchia statilinus within open lands in the study area "Döberitzer Heide" as a result of linking habitat Kriging with PLSR axis models for a pixel-wise prediction

tree locations is not dependent on specific plant community membership, the heathland distance is well projected to ordinated plot locations. This accords to expert estimations, identifying Calluna vulgaris as to be one of the most important host plants for the adult Hipparchia statilinus (Kühne and Gelbrecht 1997; Steiner and Trusch 2000).

In contrast, existing knowledge about the importance of the parameter "distance to forests" was vague. Due to observations of Kühne and Gelbrecht (1997) of Hipparchia resting on pine stems at forest borders, we considered a short distance to the forest border to be anticipated by our target species. On the other hand, the species is known to be adapted to large-scale open sandy habitats that are connected and not intersected by forests. However, there were no findings about a significant correlation between Hipparchia habitats and the parameter "distance to forests." We therefore consider it useful to conduct further studies applying landscape metrics evaluating the importance of habitat connectivity.

In total, habitat variance could be explained by up to $81 \%$ with spectral variables at a spatial resolution of $2 \times 2 \mathrm{~m}$. and half of the tested parameters could be declared as to be significantly correlated with Hipparchia occurrence probability. In summary, Hipparchia habitats are preferentially situated on high (e.g., ground moraine) areas with relatively steep slopes directed to the south. The distribution of Calluna vulgaris and hence the distance to food plants can be seen as a significant habitat factor, as well. The occurrence of Hipparchia statilinus becomes unlikely the more the distance to Calluna vulgaris increases.

\section{Conclusion}

In conclusion, we can state that we were able to predict occurrence probabilities of an endangered butterfly species on a former military area basing on hyper spectral remote sensing methods and explain habitat variances up to $81 \%$. We first presented the characteristic floristic composition by hyper spectral airborne imagery for our study area Döberitzer Heide in Eastern Germany to further analyze characteristics of the geographic plot locations of presence/absence data in a three-dimensional ordination space by using statistical methods. Finally, we developed an appropriate variogrammodel including environmental predictor variables and point out the variables "bare ground," "pioneer stages," "elevation," "slope," "northness" and "distance Calluna" as parameters considerably determining habitat qualities for Hipparchia statilinus at military areas. We emphasize using Hipparchia statilinus as an indicator for the evaluation of the conservation status of Natura 2000 habitat type 2330 (European Habitat Directive: inland dunes with open Corynephorus and Agrostis grasslands). Schröder et al. (2008) particularly point out that the preservation of habitat type 2330 in Germany is almost exclusively limited to military training areas. The European Commission (2005a, b) is aware of the importance of military training areas in concern of nature conservation. Anyway, the abandonment of former military areas is considerably affecting a wide range of species (Tucker and Heath 1994; Poole et al. 1998) and is a major threat for European butterflies as our target species Hipparchia statilinus (Van Swaay et al. 2010). Due to the amount of dry open landscapes, military conversion areas are known to be suitable habitats for Hipparchia statilinus. Unfortunately, the demand on monitoring activities is confronted by the inaccessibility of military areas as well as a lack of information concerning habitat preferences of target or indicator species. We assure that the here presented approach can considerably facilitate Natura 2000 monitoring and management at military areas. Remote sensing maps are often considered to be the end-product of an investigation rather than an instrument and help for more specific conservation efforts (Andrew and Ustin 2009). With this study, we aim to demonstrate possibilities for future cooperations of the remote sensing community and ecologists. We absolutely encourage testing transferability to other military areas. 

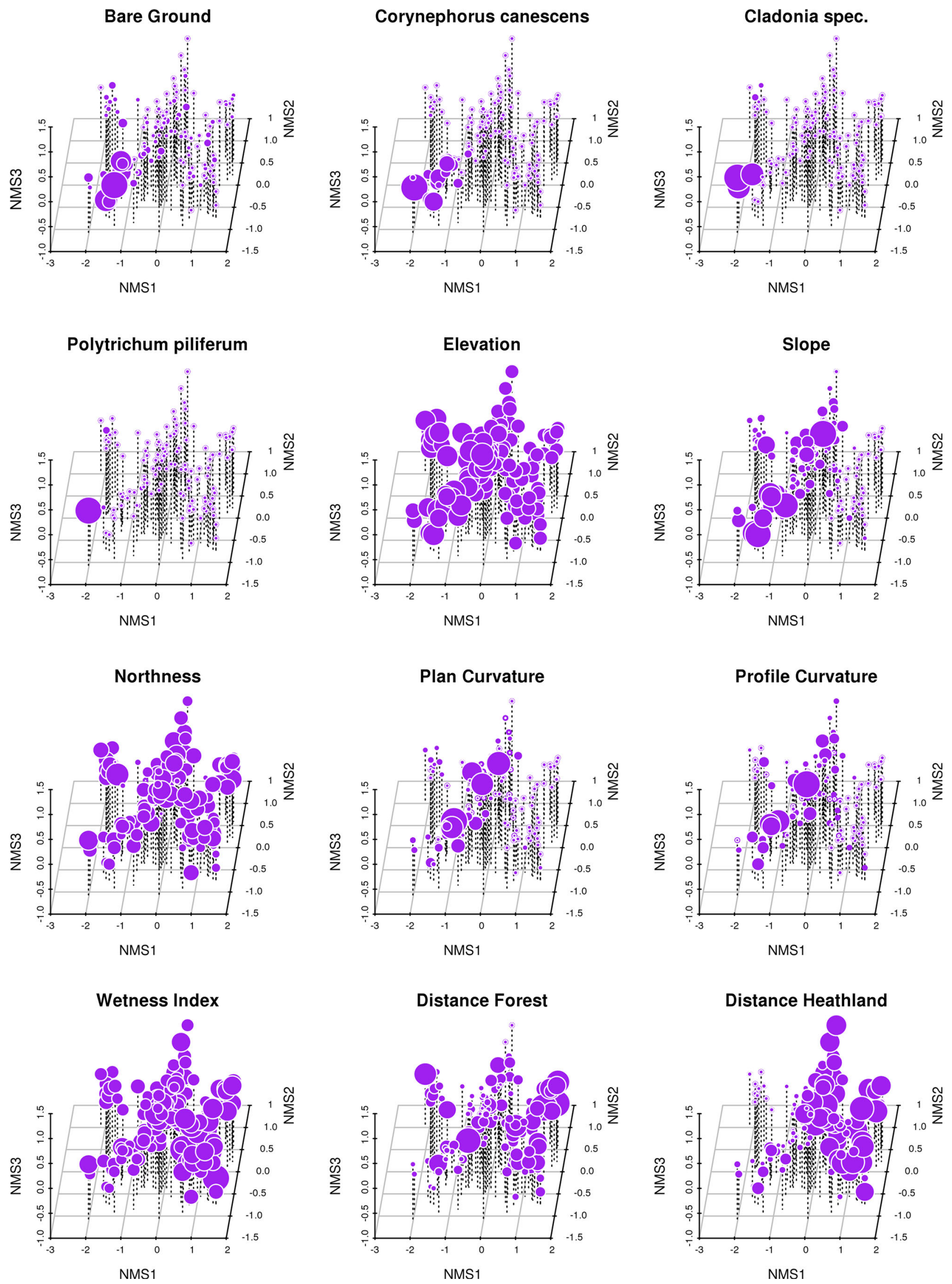
4Fig. 9 Ecological gradient analysis for predefined environmental predictor variables; plot size is positively correlated with gradient range on field plots

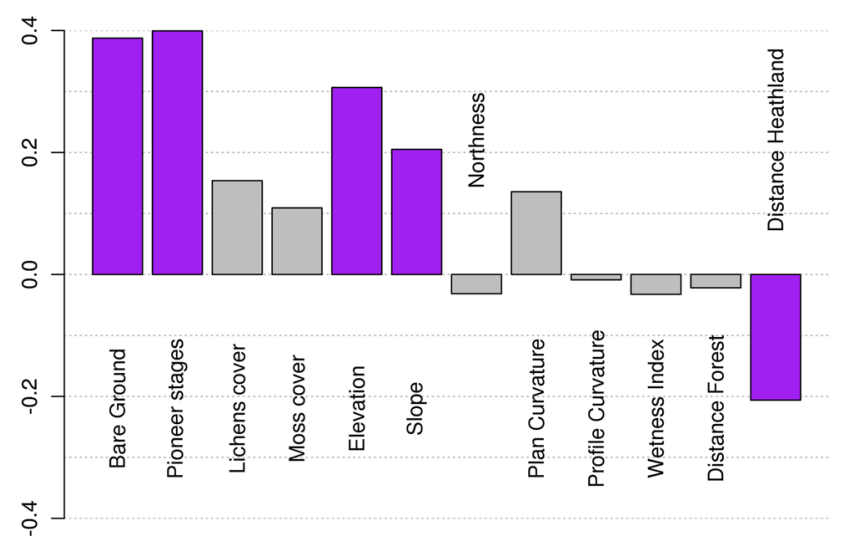

Fig. 10 The Pearson product moment correlation between occurrence probability of Hipparchia statilinus and environmental gradients in ordination space; purple color indicates significant relation with $p<0.05$ in linear regression

Acknowledgments We thank the team of the Sielmanns Naturlandschaft Döberitzer Heide $\mathrm{gGmbH}$ for supporting our studies. Special thanks to Martin Wiemers, Gregor Stuhldreher, Oliver Schmitz, Matthias Kühling, Klaus Dörbandt and Bernd Schulze who shared expert knowledge as well as to all the others enabling great butterfly-days at the study area. We also thank the University of Potsdam and the Helmholtz Centre Potsdam (GFZ) for supporting a $\mathrm{PhD}$ scholarship.

\section{References}

Andrew M, Ustin S (2009) Habitat suitability modelling of an invasive plant with advanced remote sensing data. Divers Distrib 15:627-640

Balbontin J (2005) Identifying suitable habitat for dispersal in Bonelli's eagle: an important issue in halting its decline in Europe. Biol Conserv 126:74-83

Bellis LM, Pidgeon AM, Radeloff VC, St-Louis V, Navarro JL, Martella MB (2008) Modeling habitat suitability for Greater Rheas based on satellite image texture. Ecol Appl 18(8):1956-1966

Binot-Hafke M, Balzer S, Becker N, Gruttke H, Haupt H,Hofbauer N, Ludwig G, Matzke-Hajek G Strauch M (2011) Rote Liste gefährdeter Tiere, Pflanzen und Pilze Deutschlands. Band 3: Wirbellose Tiere (Teil 1) Bundesamt für Naturschutz, Naturschutz und Biologische Vielfalt 70 (3), Bonn-Bad Godesberg

Carvell C (2002) Habitat use and conservation of bumblebees (Bombus spp.) under different grassland management regimes. Biol Conserv 103(1):33-49

Clark RN, King TVV, Gorelick NS (1987) Automatic continuum analysis of reflectance spectra. In: Proceedings of third AIS workshop, 2-4 June, 1987, JPL Publication 87-30. Jet Propulsion Laboratory, Pasadena, CA, pp 138-142

Cumming GS (2000) Using habitat models to map diversity: panAfrican species richness of ticks (Acari: ixodida). J Biogeogr 27(2):425-440
Eitschberger U, Reinhardt R, Steiniger H (1991) Wanderfalter in Europa. In: Gesellschaft zur Förderung der Erforschung von Insektenwanderungen in Deutschland e.V., München (Hrsg.): Atalanta. Nr. 22, DFZS, Marktleuthen

European Commission (2005a) Note to the Habitats Committee. Assessment, monitoring and reporting of conservation statuspreparing the 2001-2007 report under Article 17 of the Habitats Directive. DocHab-04-03/03 re.3.Brussels: European Commission

European Commission (2005b) LIFE focus/LIFE, Natura 2000 and the military. http://ec.europa.eu/environment/life/publications/ lifepublications/lifefocus/documents/military_en.pdf

European Commission (2009) Directive 2009/147/EC of the European Parliament and of the Council of 30 November 2009 on the conservation of wild birds (79/409/EEC)

Frick A (2007) Beiträge höchstauflösender Satellitenfernerkundung zum FFH-Monitoring-Entwicklung eines wissensbasierten Klassifikationsverfahrens und Anwendung in Brandenburg. Dissertation, Technische Universität Berlin

Frick A, Weyer G, Kenneweg H, Kleinschmit B (2005) A knowledgebased approach to vegetation monitoring with QuickBird imagery. In: Proceedings of the ISPRS Workshop 2005: highresolution earth imaging for geospatial information, Hannover, 17-20 May, 2005

Gelbrecht J, Dommain R, Rödel I, Renner W (2001a) Aktueller Stand der Verbreitung von Hipparchia statilinus (HUFNAGEL 1766) in Brandenburg. Lepidoptera:Satyrinae Märkische Ent Nachr 3(1):21-25

Gelbrecht J, Eichstädt D, Göritz U, Kallies A, Kühne L, Richert A, Rödel I, Sobczyk T, Weidlich M (2001b) Gesamtartenliste und Rote Liste der Schmetterlinge („Macrolepidoptera“) des Landes Brandenburg. Naturschutz und Landschaftspflege in Brandenburg 10(3) Beilage:1-62

Gottschalk TK, Huettmann F, Ehlers M (2005) Thirty years of analysing and modelling avian habitat relationships using satellite imagery data: a review. Int $J$ Remote Sens 26(12):2631-2656

Gross JE, Hansen AJ, Goetz SJ, Theobald DM, Melton FS, Piekielek NB, Nemani RR (2012) Remote sensing for inventory and monitoring of U.S. National Parks. In: Wang Y (2012) Remote sensing of protected lands. pp 29-56. CRC Press, Boca Raton

Havlick DG (2011) Disarming nature: converting military lands to wildlife refuges. Geogr Rev 101(2):183-200 (the American Geographical Society of New York)

Hengl T, Toomanian N, Reuter HI, Malakouti MJ (2007) Methods to interpolate soil categorical variables from profile observations: lessons from Iran. Geoderma 140(4):417-427

Hepinstall JA, Sander SA (1997) Using Bayesian statistics, thematic mapper satellite imagery, and breeding bird data to model bird species probability of occurence in Maine. Photogram Eng Remote Sens 63:1231-1237

Kerr JT, Ostrovsky M (2003) From space to species: ecological applications for remote sensing. Trends Ecol Evol 18(6):299-305

Kruskal JB (1964) Multidimensional scaling by optimizing goodness of fit to a nonmetric hypothesis. Psychometrika 29(1):1-27

Kühne L, Gelbrecht J (1997) Zur Faunistik und Ökologie der Schmetterlinge in der Mark Brandenburg. VII. Verbreitung und Ökologe von Hipparchia statilinus -in der Mark Brandenburg und den südlich angrenzenden Gebieten der Oberlausitz. (Lep., Satyrldae). Ent Nachr Ber 41:27-32

Lausch A, Pause M, Merbach I, Zacharias S, Doktor D, Volk M, Seppelt R (2013) A new multi-scale approach for monitoring vegetation using remote sensing-based indicators in laboratory, field and landscape. Environ Monit Assess 185(2):1215-1235

Luft L, Neumann C, Freude M, Blaum N, Jeltsch F (2014) Hyperspectral modeling of ecological indicators-a new 
approach for monitoring former military training areas. Ecol Ind 46:264-285

LUGV (2011) Bericht zum Workshop Monitoring in der Döberitzer Heide, conference transcript Landesumweltamt Brandenburg http://www.mugv.brandenburg.de/cms/media.php/lbm1.a.2338. de/doeberitz_fb_123_web.pdf

Luoto M, Kuussaari M, Toivonen T (2002) Modeling butterfly distribution based on remote sensing data. J Biogeogr 29:1027-1037

Luoto M, Virkkala R, Heikkinen R, Rainio K (2004) Predicting bird species richness using remote sensing in boreal agriculturalforest mosaic. Ecol Appl 14:1946-1962

Matheron G (1963) Principles of geostatistics. Econ Geol 58(8):1246-1266

Matheron G (1971) The theory of regionalized variables and its applications, vol 5. Ecole nationale supérieure des mines de Paris

Mladenoff DJ, Sickley TA, Haight RG, Wydeve AP (1995) A regional landscape analysis and prediction of favorable gray wolf habitat in Northern Great Lakes Region. Conserv Biol 9(2):279-294

Morrison ML, Marcot BG, Mannan RW (1998) Wildlife-habitat relationships - concepts and applications, 2nd edn. University of Wisconsin Press, Madison

Mücher CA, Kooistra L, Vermeulen M, Borre JV, Haest B, Haveman B (2013) Quantifying structure of Natura 2000 heathland habitats using spectral mixture analysis and segmentation techniques on hyperspectral imagery. Ecol Ind 33:71-81

Nagelkerke NJ (1991) A note on a general definition of the coefficient of determination. Biometrika 78(3):691-692

Neumann C (2010) Synthese von ökologischer Gradientenanalyse und hyperspektraler Fernerkundung zum Monitoring naturschutzfachlich bedeutsamer Offenlandschaften. Diploma thesis, University of Potsdam

Neumann C, Weiß G, Itzerott S, Kühling M, Fürstenow J, Luft L, Nitschke P (2013) Entwicklung und Erprobung eines innovativen, naturschutzfachlichen Monitoringverfahrens auf der Basis von Fernerkundungsdaten am Beispiel der Döberitzer Heide, Brandenburg: Abschlussbericht, (Scientific Technical Report, 13/02). Deutsches GeoForschungsZentrum GFZ, Potsdam

Osborne PE, Alonso JC, Bryant RG (2001) Modeling landscape-scale habitat use using GIS and remote sensing: a case study with great bustard. J Appl Ecol 38:458-471

Poole A, Pienkowski M, McCracken DI, Petretti F, Brédy C and Deffeyes C (1998) Mountain livestock farming and EU policy development. In: Proceedings of the fifth European forum on nature conservation

Posillico M, Meriggi A, Pagnin E, Lovari S, Russo L (2004) A habitat model for brown bear conservation and land use planning in central Apennines. Conserv Biol 118:141-150

Rocchini D, Balkenhol N, Carter GA, Foody GM, Gillespie TW, He KS, Kark S, Levin N, Lucas K, Luoto M, Nagendra H, Oldeland J, Ricotta C, Southworth J, Neteler M (2010) Remotely sensed spectral heterogeneity as a proxy of species diversity: recent advances and open challenges. Ecol Inform 5:318-329

Sardà-Palomera F, Puigcerver M, Brotons L, Rodríguez-Teijeiro JD (2012) Modelling seasonal changes in the distribution of Common quail Coturnix coturnix in farmland landscapes using remote sensing. Ibis 154:703-713

Savitzky A, Golay MJ (1964) Smoothing and differentiation of data by simplified least squares procedures. Anal Chem 36(8):1627-1639

Schmidtlein S, Feilhauer H, Bruelheide H (2012) Mapping plant strategy types using remote sensing. J Veg Sci 23(3):395-405
Schröder B (2000) Zwischen Naturschutz und Theoretischer Ökologie: Modelle zur Habitateignung und räumlichen Populationsdynamik für Heuschrecken im Niedermoor. Dissertation, TU Braunschweig

Schröder B, Reineking B (2004) Modellierung der Art-HabitatBeziehung-ein Überblick über die Verfahren der Habitatmodellierung. In Dormann CF, Blaschke T, Lausch A, Schröder B, Söndgerath D (2003) Habitatmodelle-Methodik, Anwendung, Nutzen. Conference transcript workshop 8-10. 10.2003,UFZ Leipzig. UFZ-transcript 9/2004, p 178

Schröder E, Balzer S, Ellwanger G (2008) Die Situation der Heiden und Sandtrockenrasen in Deutschland. Abhandlungen aus d. Westfälischen Museum f. Naturkunde 70 (3/4):245-260

Schubert R, Hilbig W, Klotz S (1995) Bestimmungsbuch der Pflanzengesellschaften Mittel- und Norddeutschlands. G. Fischer Vlg, Jena

Simmat U (2011) Eingeführte Großsäuger. In: LUGV (ed) Monitoring in der Döberitzer Heide. Conference transcript LUGV Brandenburg, pp 55-61

Steiner R, Trusch R (2000) Eiablageverhalten und -habitat von Hipparchia statilinus in Brandenburg (Lepidoptera: Nymphalidae: Satyrinae)/Egg-laying Behaviour of Hipparchia statilinus in Eastern Germany (Lepidoptera; Nymphalidae: Satyrinae). Stuttgarter Beiträge zur Naturkunde, Serie A (Biologie) 606

Tucker MG, Heath MF (1994) Birds in Europe: their conservation status, vol 3. BirdLife International, BirdLife Conservation Series, Cambridge

Van Swaay C, Cuttelod A, Collins S, Maes D, Munguira ML, Šašić M, Settele J, Verovnik R, Verstrael T, Warren M, Wiemers M, Wynhof I (2010) European red list of butterflies. Publications Office of the European Union, Luxembourg

Vanden Borre JV, Paelinckx D, Müchen CA, Kooistra L, Haest B, de Blust G, Schmidt AM (2011) Integrating remote sensing in Natura 2000 habitat monitoring: prospects on the way forward. J Nature Conserv 19:116-125

Walker K, Pywell R (2000) Grassland communities on Salisbury Plain Training Area (SPTA): results of the ITE ecological survey. Wiltshire Bot 3:15-27

Wang Y (2012) Remote sensing of protected lands. CRC Press, Taylor \& Francis Group, Boca Raton

Wang H, Gao J, Ren L-L, Kong Y, Li H, Li L (2013) Assessment of the red-crowned crane habitat in the Yellow River Delta Nature Reserve, East China. Reg Environ Change 13:115-123

Warren SD, Holbrook SW, Dale DA, Whelan NL, Elyn M, Grimm W, Jentsch A (2007) Biodiversity and the heterogeneous disturbance regime on military training lands. Restor Ecol 15(4):606-612

Weidemann H-J (1995) Tagfalter beobachten, bestimmen. Naturbuchverlag, Augsburg

Weiers S, Bock M, Wissen M, Rossner G (2004) Mapping and indicator approaches for the assessment of habitats at different scales using remote sensing and GIS methods. Landsc Urban Plan 67(1):43-65

Williams CB(1961) Die Wanderflüge der Insekten. Einführung in das Problem des Zugverhaltens der Insekten unter besonderer Berücksichtigung der Schmetterlinge. Paul Parey, Hamburg, Berlin

Wold H (1966) Estimation of principal components and related models by iterative least squares. Multivar Anal 1:391-420 